\title{
Produção in vitro e expressão gênica de IGF-I e IGF-II em embriões de fêmeas Nelore submetidas a administrações de somatotropina recombinante bovina
}

\author{
In vitro production and gene expression of IGF-I and IGF-II in embryos from Nelore females \\ submitted to administrations of recombinant bovine somatotropin \\ Producción in vitro y expresión génica de IGF-I e IGF-II en embriones de hembras Nelore \\ sometidas a administraciones de somatotropina recombinante bovina
}

Recebido: 24/02/2021 | Revisado: 03/03/2021 | Aceito: 07/03/2021 | Publicado: 15/03/2021

Rafael Soares dos Anjos
ORCID: https://orcid.org/0000-0002-5979-5229
Universidade Federal Rural de Pernambuco, Brasil
E-mail: rafa_dos_anjos@hotmail.com
Kaio César Simiano Tavares
ORCID: https://orcid.org/0000-0003-3919-161X
Universidade de Fortaleza, Brasil
E-mail: kaiocstavares@ @otmail.com
Leonardo Tondello Martins
Universidade de Fortaleza, Brasil
E-mail: leotondello@yahoo.com.br
Luís Henrique de Aguiar
ORCID: https://orcid.org/0000-0001-7885-7408
Universidade de Fortaleza, Brasil
E-mail: luizaguiarvet@ gmail.com
Marcelo Bertolini
ORCID: https:/orid.org/000-0003-624-8907
ORCID: https://orcid.org/0000-0003-0340-6148
Universidade Federal do Rio Grande do Sul, Brasil
E-mail: mbertolini @ymail.com
Emanuel Felipe Oliveira Filho
ORCID: https://orcid.org/0000-0003-2836-5549
Universidade Federal Rural de Pernambuco, Brasil
E-mail: felipe130188@ gmail.com
Gustavo Ferrer Carneiro
ORCID: https://orcid.org/0000-0002-9466-9500
Universidade Federal Rural de Pernambuco, Brasil
E-mail: carneirogustavo1@ gmail.com

\begin{abstract}
Resumo
Com o presente trabalho, objetivou-se estudar a influência da somatotropina recombinante bovina (rbST) sobre a quantidade e qualidade de oócitos aspirados in vivo, produção embrionária e expressão gênica dos fatores de crescimento semelhantes à insulina (IGFs) tipos I e II em embriões produzidos in vitro de fêmeas bovinas da raça Nelore. Cinco vacas foram tratadas com duas administrações de $2 \mathrm{~mL}$ de solução salina como placebo, com intervalo de catorze dias entre elas, sendo a primeira administração realizada dezenove e a segunda cinco dias antes das aspirações foliculares; decorridos trintas dias destas aspirações, em sistema crossover, o mesmo protocolo foi utilizado nesses cinco animais sendo, neste caso, a solução salina substituída por $500 \mathrm{mg}$ de rbST, com o intuito de efetuar-se comparações entre os tratamentos. A partir dos oócitos recuperados, realizou-se a produção in vitro de embriões (PIVE), sendo todas as etapas que envolvem este processo analisadas e com posterior realização de reações em cadeia da polimerase em tempo real (qPCRs) para expressões gênicas de IGF-I e IGF-II nos blastocistos produzidos. Observou-se que a rbST, ainda que numericamente tenha influenciado positivamente sobre os parâmetros estudados, não exerceu influência significativa sobre a quantidade e qualidade de oócitos aspirados in vivo, produção embrionária e expressão gênica de IGF-I e IGF-II em embriões produzidos in vitro de fêmeas bovinas da raça Nelore. Palavras-chave: Embriões; IGF-I; IGF-II; Nelore; PIVE; rbST.
\end{abstract}

\footnotetext{
Abstract

The present work aimed of studying the influence of recombinant bovine somatotropin (rbST) on quantity and quality of in vivo aspirated oocytes, embryo production and gene expression of insulin-like growth factors (IGFs) types I and II in in vitro produced embryos from bovine females of Nelore breed. Five cows were treated with two
} 
administrations of $2 \mathrm{~mL}$ of saline solution as placebo, with an interval of 14 days between them, being the first administration held 19 and the second 5 days before follicular aspirations; within 30 days after these aspirations, in a crossover design, the same protocol was used in these five animals being, in this case, the saline solution replaced by $500 \mathrm{mg}$ of rbST in order to perform comparisons between treatments. From retrieved oocytes, in vitro production (IVP) was performed, being all stages involving this process evaluated with subsequent achievement of polymerase chain reactions in real time (qPCRs) for gene expression of IGF-I and IGF-II in produced blastocysts. It was observed that the rbST, although having a numerical increase, did not show significant influence, on the parameters studied, on the quantity and quality of in vivo aspirated oocytes, embryo production and gene expression of IGF-I and IGF-II in in vitro produced embryos from bovine females of Nelore breed.

Keywords: Embryos; IGF-I; IGF-II; IVP; Nelore; rbST.

\section{Resumen}

Este estudio tuvo como objetivo estudiar la influencia de la somatotropina recombinante bovina (rbST) en la cantidad y calidad de los ovocitos aspirados in vivo, la producción embrionaria y la expresión génica de los factores de crecimiento insulínicos (IGFs) tipos I y II en embriones producidos in vitro a partir de Nelore hembras bovinas. Se trataron cinco vacas con dos administraciones de $2 \mathrm{~mL}$ de solución salina como placebo, con un intervalo de catorce días entre ellas, siendo la primera administración diecinueve y la segunda cinco días antes de las aspiraciones foliculares; a los treinta días de estas aspiraciones, en un sistema cruzado, se utilizó el mismo protocolo en estos cinco animales, en cuyo caso se sustituyó la solución salina por 500mg de rbST, con el fín de realizar comparaciones entre tratamientos. A partir de los ovocitos recuperados se llevó a cabo la producción de embriones in vitro (PIVE), analizándose todas las etapas de este proceso y con la posterior realización de reacciones en cadena de la polimerasa en tiempo real (qPCRs) para IGF-I e IGF-II en los blastocistos producidos. Se observó que la rbST, aunque numéricamente influyó positivamente en los parámetros estudiados, no tuvo una influencia significativa en la cantidad y calidad de ovocitos aspirados in vivo, producción embrionaria y expresión génica de IGF-I e IGF-II en embriones producidos in vitro de hembras bovinas Nelore.

Palabras clave: Embriones; IGF-I; IGF-II; Nelore; PIVE; rbST.

\section{Introdução}

O Brasil possui o maior rebanho bovino comercial do Mundo, com mais de 212 milhões de cabeças (IBGE, 2019). Cerca de $80 \%$ do rebanho nacional é composto por animais de raças zebuínas (Bos taurus indicus), que são de comprovadas rusticidade e capacidade de adaptação às condições ambientais e climáticas adversas existentes em grande parte do território brasileiro - com destaque para a raça Nelore, por ocupar 90\% do mencionado montante (ABIEC, 2020).

Segundo Kozicki et al. (2005), a otimização da eficiência reprodutiva é um dos principais fatores que contribuem para o incremento na eficiência produtiva e lucratividade dos rebanhos bovinos. Com o intuito de aumentar os índices reprodutivos na atividade pecuária, atualmente faz-se uso de biotécnicas como a aspiração folicular ou ovum pick up (OPU) seguida da produção in vitro de embriões, ou PIVE (Ravedutti \& Vechiato, 2010).

Na busca de melhores resultados na reprodução animal, a utilização de fármacos exógenos vem aumentando consideravelmente na última década. Pesquisa-se atualmente a utilização da somatotropina recombinante bovina (rbST), tida como substância que acarreta aumento de receptores para os fatores de crescimento semelhantes à insulina, ou IGFs (Lucy, 2000). De acordo com Moreira et al. (2002), a rbST contribui de forma positiva nas taxas de fecundação in vitro (FIV) e qualidade embrionária, além de acelerar a taxa de desenvolvimento embrionário, acarretando maior quantidade de blastocistos (Ramos et al., 2007).

Em se tratando do sistema IGF e a produção de embriões, os IGFs são de grande importância para os estágios iniciais da foliculogênese, já que a desativação de genes do sistema em questão levou ao comprometimento severo do desenvolvimento folicular pré-antral a antral (Buratini, 2006) e, segundo Lonergan et al. (2003), tanto os IGFs tipos I e II como seus receptores (IGF-IR e IGF-IIR) são expressos em oócitos e embriões bovinos e ovinos produzidos in vitro.

Tais citações despertaram o interesse em, no presente trabalho, estudar o efeito da rbST sobre a quantidade e qualidade de oócitos aspirados in vivo, produção embrionária e expressão gênica de IGF-I e IGF-II em embriões produzidos in vitro de fêmeas bovinas da raça Nelore. 


\section{Material e Métodos}

O experimento, estando de acordo com os princípios éticos de experimentação animal da Comissão de Bioética da Faculdade Pio Décimo sob o protocolo n ${ }^{\circ} 33 / 2012$, foi realizado entre os meses de setembro de 2013 e janeiro de 2014 , na Fazenda Santa Luzia, propriedade localizada no município de Vitória de Santo Antão, na Zona da Mata de Pernambuco (Latitude $08^{\circ} 07^{\prime} 05^{\prime \prime} \mathrm{S}$ e Longitude $35^{\circ} 17^{\prime} 29^{\prime \prime} \mathrm{W}$ ) - no condizente às OPUs, rastreamento, seleção, classificação e envase de oócitos para transporte ao laboratório de PIVE; e na Universidade de Fortaleza, em Fortaleza/CE, no referente à PIVE e avaliação das expressões gênicas.

Foram utilizadas cinco fêmeas bovinas da raça Nelore, puras de origem (PO), com idades entre seis e doze anos, multíparas, cíclicas, em período pós-puerperal, escore corporal variando de 3 a 3,5 (em escala de 1 a 5) e peso vivo médio de $504,5 \mathrm{Kg}$, submetidas a exame ginecológico completo anteriormente às atividades experimentais. Os animais foram mantidos em sistema de criação extensivo, em pastagens compostas por Brachiaria brizantha e Brachiaria decumbens, com fornecimento de água e sal mineral ad libitum. O experimento foi conduzido com metodologia quantitativa a respeito do objetivo geral, conforme descrita por Pereira et al. (2018).

O delineamento experimental foi estabelecido em sistema crossover, inteiramente ao acaso, onde as cinco vacas, em um primeiro momento, compuseram o grupo controle e receberam duas administrações de $2 \mathrm{~mL}$ de solução salina como placebo, via subcutânea, na fossa ísquio-retal, com intervalo de catorze dias entre elas, sendo a primeira administração dezenove e a segunda cinco dias antes da data das OPUs; sendo que, após trinta dias destas OPUs, tais animais foram invertidos em grupo tratamento e receberam duas administrações de 500mg de rbST (Boostin ${ }^{\circledR}$, Coopers Saúde Animal, Brasil), via subcutânea, na fossa ísquio-retal, com intervalo de catorze dias entre elas, sendo a primeira administração dezenove e a segunda cinco dias antes da data das OPUs.

Com o intuito de evitar a presença de corpo lúteo quando das aspirações, fez-se uso de duas administrações de $500 \mu \mathrm{g}$ de cloprostenol $\left(\right.$ Sincrocio $^{\circledR}$, Ouro Fino, Brasil) por animal, via intramuscular, com intervalo de onze dias entre as administrações, sendo a primeira dezesseis e a segunda cinco dias antes das OPUs. Para sincronizar a onda folicular das fêmeas, com a finalidade de homogeneizar os grupos quanto ao momento do ciclo estral: cinco dias antes das OPUs fez-se uso de $3 \mathrm{mg}$ de norgestomet (Crestar ${ }^{\circledR}$, Intervet, Brasil), em forma de implante auricular, inserido na face externa da orelha de cada animal e administração de $2 \mathrm{mg}$ de benzoato de estradiol (Gonadiol ${ }^{\circledR}$, Coopers Saúde Animal, Brasil) por vaca, via intramuscular. Os implantes auriculares foram removidos no dia das aspirações.

A PIVE foi realizada conforme Bertolini et al. (2002), exceto no que diz respeito aos métodos para obtenção de oócitos e seleção de espermatozoides viáveis utilizados, quando no presente estudo, para tanto, fez-se uso de OPU e gradiente Percoll $^{\circledR}$, respectivamente. Decorridos sete dias das FIVs os blastocistos produzidos foram lavados em solução de PBS $+0,1 \%$ de álcool polivinílico, posteriormente acondicionados em tubos criogênicos de 0,2mL (contendo quantidade mínima da referida solução de lavagem) e conservados em ultrafreezer a $-80^{\circ} \mathrm{C}$ para posterior avaliação das expressões gênicas.

No condizente às expressões gênicas: a extração de ácido ribonucleico (RNA) e síntese de ácido desoxirribonucleico complementar (cDNA), a partir dos blastocistos, foram realizadas seguindo o protocolo recomendado pelo fabricante do kit SuperScript ${ }^{\circledR}$ III Platinum ${ }^{\circledR}$ CellsDirect Two-Step qRT-PCR Kit (Invitrogen, EUA). A realização das expressões gênicas per si foi mediante uso da reação em cadeia de polimerase em tempo real (qPCR).

Para as qPCRs dos genes IGF-I e IGF-II, utilizou-se o controle endógeno RPS9, com os seguintes iniciadores, de acordo com a Tab. 1 abaixo: 
Tabela 1. Detalhes dos iniciadores utilizados para as qPCRs dos genes IGF-I, IGF-II e controle endógeno RPS9.

\begin{tabular}{cc}
\hline Gene & Sequência dos iniciadores (5' 3’’ $^{\prime}$ \\
\hline IGF-I & F-CATTCATTCAGCAGGCTTGTCTAA \\
& R-TGATGGAGAAGGGAGTGGGATA \\
IGF-II & F-TCTACTTCAGCCGACCATCCA \\
& R-TTCGGAAGCAACACTCTTCCA \\
RPS9 & F-GAGCTGGGTTTGTCGCAAAA \\
& R-GGTCGAGGCGGGACTTCT \\
\hline
\end{tabular}

Fonte: Autores.

A Tabela 1 apresenta os genes utilizados bem como descreve cada sequência dos iniciadores. Todas as reações foram processadas utilizando-se o Power SYBR ${ }^{\circledR}$ Green Mastermix (Applied Biosystems, EUA) e o termociclador StepOne ${ }^{\mathrm{TM}}$ RealTime PCR System (Applied Biosystems, EUA) em duplicatas. Para IGF-I foram utilizados 400nM de cada iniciador, $1 \mu \mathrm{L}$ de cDNA e o seguinte programa de ciclos e temperaturas: $95^{\circ} \mathrm{C}$ por 20 segundos, seguido por 55 ciclos de $95^{\circ} \mathrm{C}$ por 30 segundos, $55^{\circ} \mathrm{C}$ por 30 segundos e $72^{\circ} \mathrm{C}$ por 30 segundos. Para o gene IGF-II foram utilizados $400 \mathrm{nM}$ de cada iniciador, $1 \mu \mathrm{L}$ de cDNA e o seguinte programa de ciclos e temperaturas: $95^{\circ} \mathrm{C}$ por 2 minutos, seguido por 50 ciclos de $95^{\circ} \mathrm{C}$ por 15 segundos e $60^{\circ} \mathrm{C}$ por 1 minuto. Posteriormente a todas as amplificações foi realizada uma curva de Melting ${ }^{\circledR} \operatorname{com}$ temperatura de $60^{\circ} \mathrm{C}$ a $95^{\circ} \mathrm{C}$ e incremento de $0.3^{\circ} \mathrm{C} /$ segundo, para verificar a identidade de cada amplicom. Os dados foram normalizados segundo Livak e Schmittgen (2001).

Para obtenção de médias relativas e erros padrão dos parâmetros analisados neste estudo, os dados foram processados no programa GraphPad Instat 3.10 ${ }^{\circledR}$ (GraphPad Software, Inc., 2009), utilizando-se o teste paramétrico t, com $95 \%$ de nível de confiança.

No condizente à análise de associação, quanto à avaliação da qualidade dos oócitos em seus diferentes graus de viabilidade, utilizou-se o teste de qui-quadrado. O nível de significância adotado foi de 5\%. O programa Epi Info 3.5.1 (Centers for Disease Control and Prevention, 2008) foi utilizado para a execução destes cálculos estatísticos.

Em relação às avaliações das taxas de clivagem e produção de blastocistos, foram descartados os oócitos de uma das vacas envolvidas no experimento (enquanto componente do grupo controle, bem como quando componente do grupo tratamento), por ter-se identificado contaminação fúngica destes entre as etapas de FIV e cultivo in vitro (CIV).

\section{Resultados e Discussão}

Observou-se, no presente estudo, que o uso da rbST não influenciou estatisticamente (p>0,05) na quantidade de oócitos totais em vacas Nelore PO. Ramos et al. (2007) também não encontraram diferença significativa entre os grupos tratamento (rbST) e controle (solução salina) no referente à quantidade de oócitos aspirados. Em contrapartida, Kozicky et al. (2005) afirmaram que a rbST age favorecendo o recrutamento folicular ovariano, o que sugere um aumento na quantidade de oócitos recuperados in vivo a partir de vacas submetidas a tratamento com a rbST.

Com relação à qualidade, estudos anteriores demonstraram que houve efeito significante em oócitos sob ação da rbST (Tripp et al., 2000). Na presente pesquisa foram observados o aumento numérico de oócitos graus I, II e III, bem como a diminuição da quantidade de oócitos degenerados no grupo tratamento em relação ao grupo controle (Tabela 2); além disso observou-se que 97,0\% dos oócitos recuperados no grupo rbST eram viáveis, que comparados ao grupo controle de solução salina este percentual atingiu o valor de 64,5\%. Resultados semelhantes foram observados por Roth et al. (2002). 
Tabela 2. Dados inerentes aos diferentes graus de viabilidade dos oócitos recuperados, a partir de fêmeas Nelore, nos grupos controle (solução salina) e tratamento (rbST).

\begin{tabular}{ccccc}
\hline \multirow{2}{*}{ Viabilidade oocitária } & \multicolumn{2}{c}{ Grupo controle (solução salina) } & \multicolumn{2}{c}{ Grupo tratamento (rbST) } \\
\cline { 2 - 5 } & F.A. & F.R. $(\%)$ & F.A. & F.R. (\%) \\
\hline Oócitos grau I & 2 & 33,3 & 4 & 66,7 \\
Oócitos grau II & 10 & 38,5 & 16 & 61,5 \\
Oócitos grau III & 8 & 42,1 & 11 & 57,9 \\
Oócitos grau IV & 0 & 0,0 & 1 & 100,0 \\
Oócitos degenerados & 11 & 91,7 & 1 & 8,3 \\
\hline
\end{tabular}

F.A. - frequência absoluta; F.R. - frequência relativa. Fonte: Autores.

A Tabela 2 apresenta as viabilidades oocitárias em seus graus, os resultados no grupo controle que utilizou a solução salina e no grupo tratamento utilizando rbST, em frequências absoluta e relativa.

Quanto às taxas de clivagem obtidas a partir deste experimento, não houve diferença significativa entre as unidades experimentais. Resultado que difere do encontrado por Ramos et al. (2007) que, ao trabalharem com vacas Gir, relataram que a administração de 160mg de rbST, quatro dias antes das OPUs, aumentou a taxa de clivagem na PIVE. É válido ressaltar que, numericamente, a taxa de clivagem neste estudo foi superior no grupo controle (50,0\%) quando comparado ao grupo tratamento $(45,4 \%)$.

Embora a taxa de clivagem no grupo controle de solução salina tenha sido superior a do grupo rbST, a taxa de produção de blastocistos foi maior neste grupo (31,8\%) que comparado àquele (12,5\%). Outros autores, como Moreira et al. (2002), sugerem que a rbST influencie positivamente na quantidade de embriões viáveis produzidos. Já Neves et al. (2005) afirmaram que a média de embriões viáveis não aumentou nos grupos tratados com rbST em comparação aos grupos não tratados.

Dados obtidos em torno da PIVE, nesta pesquisa, estão expostos na Tabela 3 a seguir:

Tabela 3. Resultados da PIVE, a partir de fêmeas Nelore, nos grupos controle (solução salina) e tratamento (rbST). Valores de oócitos totais e viáveis estão expressos em médias \pm E.P.M.

\begin{tabular}{ccc}
\hline \multirow{2}{*}{ Parâmetros } & \multicolumn{2}{c}{ Grupos } \\
\cline { 2 - 3 } & Controle (solução salina) & Tratamento (rbST) \\
\hline Oócitos totais & $6,2 \pm 1,2$ & $6,6 \pm 2,0$ \\
Oócitos viáveis & $4,0 \pm 0,8$ & $6,4 \pm 2,0$ \\
Clivagem (\%) & 50,0 & 45,4 \\
Produção de blastocistos (\%) & 12,5 & 31,8 \\
\hline
\end{tabular}

Fonte: Autores.

A Tabela 3 expõe os resultados da PIVE nos grupos controle e tratamento, além dos valores de oócitos totais e viáveis. Quanto às expressões gênicas: não houve expressão do gene IGF-I em quaisquer dos blastocistos dos grupos em estudo. O que pode ser explicado pela redução na quantidade de transcritos do sistema IGF, à medida que o embrião se desenvolve, como sendo uma característica normal em embriões bovinos (McHughes et al., 2009). A respeito das expressões do IGF-II: não houve diferença significativa em ambos os grupos (Figura 1), ainda que o gene tenha expressado bem nos embriões em questão. Salientando que a expressão de IGF-II está diretamente relacionada com a regulação do crescimento e 
diferenciação celular, apresentando ainda, um papel mitogênico e antiapoptótico nos embriões em estádios iniciais de desenvolvimento (Riley \& Moley, 2006).

Figura 1. Níveis de expressão do gene IGF-II, em blastocistos de fêmeas Nelore, nos grupos controle (solução salina) e tratamento (rbST). Valores expressos em médias \pm E.P.M.

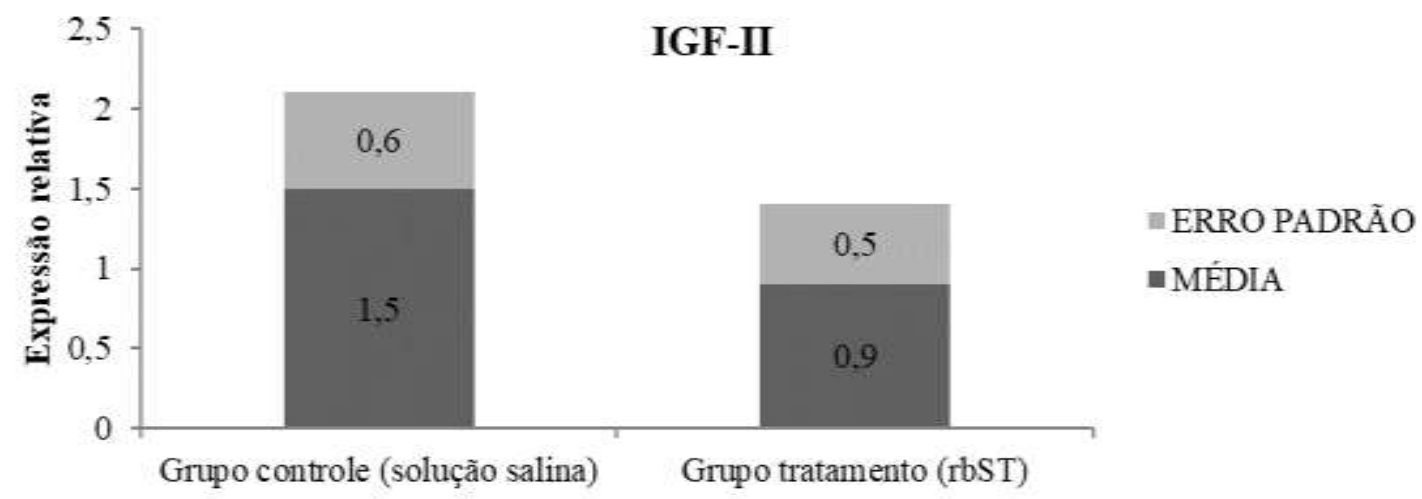

Fonte: Autores.

A Figura 1 expõe a expressão relativa no grupo controle e no grupo tratamento, bem como os resultados encontrados com o erro padrão.

\section{Conclusões}

O tratamento com duas administrações de 500mg de rbST, com intervalo de catorze dias entre elas, sendo a primeira administração realizada dezenove e a segunda cinco dias antes das OPUs, não exerceu influência significativa sobre a quantidade e qualidade de oócitos aspirados in vivo, produção embrionária e expressão gênica de IGF-I e IGF-II em embriões produzidos in vitro de fêmeas bovinas da raça Nelore. Todavia, numericamente, foi observado efeito positivo da rbST na quantidade e qualidade de oócitos aspirados in vivo, bem como sobre à produção in vitro de blastocistos. Desta forma, maiores estudos sobre a utilização de rbST devem ser desenvolvidos nas mais variadas espécies a fim de obter uma maior gama de conhecimento sobre o assunto.

\section{Referências}

ABIEC. (2020). Associação Brasileira das Indústrias Exportadoras de Carnes. Rebanho Bovino Brasileiro. <http://www.abiec.com.br/3_rebanho.asp>.

Bertolini, M., Beam, S. W., Shim, H., Bertolini, L. R., Moyer, A. L., Famula, T. R., \& Anderson, G. B. (2002). Growth, development, and gene expression by in vivo- and in vitro-produced day 7 and 16 bovine embryos. Molecular Reproduction and Development. 63(3), 318-328.

Buratini Jr., J. (2006). Foliculogênese em bovinos; In: $2^{\circ}$ Simpósio Internacional de Reprodução Animal Aplicada, 2, 2006, Londrina - PR. Anais... Londrina PR, 55-62.

IBGE. (2019). Instituto Brasileiro de Geografia e Estatística. Banco de Dados. <http://ibge.gov.br/>.

Kozicki, L. E., Segui, M. S., Fantini Filho, J. C., Prado, F. R. A., Matté, F., Glaser Jr., P., \& Weiss, R. R. (2005). A somatotropina bovina (bST) e sua relação com o recrutamento folicular ovariano durante o ciclo estral de vacas. Archives of Veterinary Science, 10(1), 35-44.

Livak, K. J., \& Schmittgen, T. D. (2001). Analysis of relative gene expression data using real-time quantitative PCR and the 2- ${ }^{-\Delta C}$ T Method. Methods, 25(4), $402-408$.

Lonergan, P., Rizos, D., Gutierrez-Adan, A., Moreira, P. M., Pintado, B., \& Boland, M. P. (2003). Temporal divergence in the pattern of messenger RNA expression in bovine embryos cultured from the zygote to blastocyst stage in vitro or in vivo. Biology of Reproduction. 69, $1424-1431$.

Lucy, M. C. (2000). Regulation of follicular growth by somatotropin and insulin-like growth factors in cattle. Journal of Dairy Science, 83, $1635-1647$. 
Research, Society and Development, v. 10, n. 3, e27010313263, 2021

(CC BY 4.0) | ISSN 2525-3409 | DOI: http://dx.doi.org/10.33448/rsd-v10i3.13263

McHughes, C. E., Springer, G. K., Spate, L. D., Li, R., Woods, R., Green, M. P., Korte, S. W., Murphy, C. N., Green, J. A., \& Prather, R. S. (2009). Identification and quantification of differentially represented transcripts in in vitro and in vivo derived preimplantation bovine embryos. Molecular Reproduction and Development, 76, 48-60.

Moreira, F., Badingal, L., Burnley, C., \& Thatcher, W. W. (2002). Bovine somatotropin increases embryonic development in superovulated cows and improves post-transfer pregnancy rates when given to lactaning recipient cows. Theriogenology, 57, 1371-1387.

Neves, E. F., Ramos, A. F., \& Marques Júnior, A. P. (2005). Pré-tratamento com somatotropina bovina (rbST) na superovulação de doadoras da raça Holandesa. Arquivo Brasileiro de Medicina Veterinária e Zootecnia, 57, 205-209.

Pereira, A. S., Shitsuka, D. M., Parreira, F. J., \& Shitsuka, R. (2018). Metodologia da pesquisa científica. UFSM. $<$ https://repositorio.ufsm.br/bitstream/handle/1/15824/Lic_Computacao_MetodologiaPesquisa-Cientifica.pdf?sequence=1>.

Ramos, A. A., Ferreira, A. M., Sá, W. F., Viana, J. H. M., Camargo, L. S. A., Polisseni, J., \& Henry, M. (2007). Efeito da somatotropina na população folicular, recuperação de oócitos e produção in vitro de embriões em vacas Gir. Revista Brasileira de Zootecnia, $36(2), 380-386$.

Ravedutti, G. C., \& Vechiato, T. A. F. (2010). Transferência de embriões: aspectos econômicos. Revista Ruminantes, Nugon, 2(13).

Riley, J. K. \& Moley, K. H. (2006). Glucose utilization and the PI3-K pathway: mechanisms for cell survival in preimplantation embryos. Reproduction, 131, 823-835.

Roth, Z., Arav, A., Braw-Tal, R., Bor, A., \& Wolfenson, A. (2002). Effect of treatment with follicle-stimulating hormone or bovine somatotropin on the quality of oocytes aspirated in the autumn from previously heat-stressed cows. Journal of Dairy Science, 85(6), 1398-1405.

Stringfellow, D. A., \& Seidel, S. M. (1998). Manual da Sociedade Internacional de Transferência de Embriões. IETS. 3.

Tripp, M. W., Ju, J. C., Hoagland, T. A., Riesen, J. W., Yang, X., \& Zinn, S. A. (2000). Influence of somatotropin and nutrition on bovine oocyte retrievel and in vitro development. Theriogenology, 53(8), 1581-1590. 